\title{
Theory and observations of Ekman flux in the chlorophyll distribution downstream of South Georgia
}

\author{
Hugh J. Venables ${ }^{1}$ and Michael P. Meredith ${ }^{1}$ \\ Received 14 October 2009; revised 5 November 2009; accepted 9 November 2009; published 12 December 2009.
}

[1] A large phytoplankton bloom occurs downstream of South Georgia, an island on the northern edge of the Scotia Sea, Atlantic sector of the Southern Ocean. This is due to natural iron fertilisation being advected downstream in the Antarctic Circumpolar Current. Mapping of SeaWiFS chl-a in dynamic height/longitude space reveals the trajectory of surface water under the dual influences of geostrophic flow and Ekman flux. A theoretical estimate of the trajectory shows good agreement with observations. The trajectory is dependent on the wind stress:mixed layer depth ratio, but independent of the latitudinal separation of dynamic height contours. The chl-a distribution suggests that iron reaches $20^{\circ} \mathrm{W}$ below the mixed layer, away from the effects of Ekman flux, but beyond the iron is confined to the surface layer. Chl-a reduces monotonically east of South Georgia with the signal detectable to $15^{\circ} \mathrm{E}$, over $3500 \mathrm{~km}$ downstream, indicating the basin-scale biogeochemical influence of the iron supply. Citation: Venables, H. J., and M. P. Meredith (2009), Theory and observations of Ekman flux in the chlorophyll distribution downstream of South Georgia, Geophys. Res. Lett., 36, L23610, doi:10.1029/2009GL041371.

\section{Introduction}

[2] The Southern Ocean has high levels of macronutrients but in most areas within it chl-a concentrations are low relative to levels that would deplete the macronutrients [Moore and Abbott, 2000; Pollard et al., 2006]. Hence the area is termed high nutrient, low chlorophyll (HNLC). It is now well established that the cause of this low chl-a is iron limitation [Blain et al., 2007; Boyd et al., 2007; Planquette et al., 2007] as there is sufficient light to support enhanced standing stocks of phytoplankton in the summer [Venables and Moore, 2009]. The region downstream of South Georgia $\left(37^{\circ} \mathrm{W}, 54.5^{\circ} \mathrm{S}\right)$ is the largest of three significant areas of enhanced chlorophyll downstream of islands (South Georgia, Kerguelen and Crozet) in the open Southern Ocean [Korb and Whitehouse, 2004; Mongin et al., 2008; Venables et al., 2007]. Iron enrichment has also been observed around South Shetland Islands at the northern end of the Antarctic Peninsula [Hewes et al., 2008]. The iron source at South Georgia is from the island itself and/or from the surrounding 100-300 m deep shelf [Whitehouse et al., 2008] with advection by the Antarctic Circumpolar Current (ACC) controlling the shape and extent of the region of enhanced chlorophyll downstream of this source.

[3] The trajectory of water below the surface layer should closely follow the geostrophic flow. In the surface layer

\footnotetext{
${ }^{1}$ British Antarctic Survey, Cambridge, UK.
}

Ekman flux is an additional net flow [Ekman, 1905]. This is predominantly northwards in the Southern Ocean due to the prevailing westerly winds [Risien and Chelton, 2008]. Theoretical Ekman currents form a spiral, supported by recent observational evidence [Lenn and Chereskin, 2009]; however the depth integrated flux is perpendicular to the wind stress, rotated to the left in the Southern Hemisphere. It is hard to observe in situ due to the presence of other ageostrophic flows (e.g., inertial currents) but these other flows have no preferred direction, enabling long-term observation of the Ekman flux to be made.

[4] Here, we examine the physical processes responsible for the trajectory of the chlorophyll plume downstream of South Georgia, specifically the relative influences of wind forcing, mixed layer depth (mld) and geostrophic flow. These are investigated from both observational and theoretical standpoints. Information is obtained on the depth of advection of iron sourced from the South Georgia shelf, and how this changes within the plume.

\section{Data}

[5] In this paper, the dynamic height product used has been derived from satellite altimetry measurements of sea surface height together with independent data of the geoid, profile data and drifter velocities [Rio and Hernandez, 2004]. The absolute dynamic topography data were produced by Ssalto/ Duacs and distributed by Aviso (http://www.aviso.oceanobs. com), with support from CNES. The ACC is seen in these data as a strong meridional gradient, increasing to the north by approximately 1.5 dynamic meters (dyn m). SeaWiFS chl-a data (level 3 mapped, version 5.2) were obtained from http://oceancolor.gsfc.nasa.gov [O'Reilly et al., 1998]. SCOW (Scatterometer Climatology of Ocean Winds) monthly zonal wind stress data are used here, following Risien and Chelton [2008]. Mixed layer depths for the region are derived from Argo float profiles. The Argo data were collected and made freely available by the International Argo Project (http://www.argo.ucsd.edu, http://argo.jcommops.org) and by the Coriolis project (http://www.coriolis.eu.org). The mld is defined here as the depth of a density change $(\Delta \sigma)$ relative to the shallowest depth $(5 \mathrm{~m}$ or $10 \mathrm{~m}) . \Delta \sigma$ is $0.05 \mathrm{~kg}$ $\mathrm{m}^{-3}$ unless otherwise stated [Venables et al., 2007]. All profiles between $12.5^{\circ} \mathrm{W}$ and $12.5^{\circ} \mathrm{E}$ with co-located dynamic height in the range 30-65 dyn $\mathrm{cm}$ were used if they passed a set of quality tests designed to filter out profiles that give spurious mixed layers.

\section{Chlorophyll Distribution}

[6] The mean spring SeaWiFS chl-a concentrations downstream of South Georgia are shown in Figure 1. The 


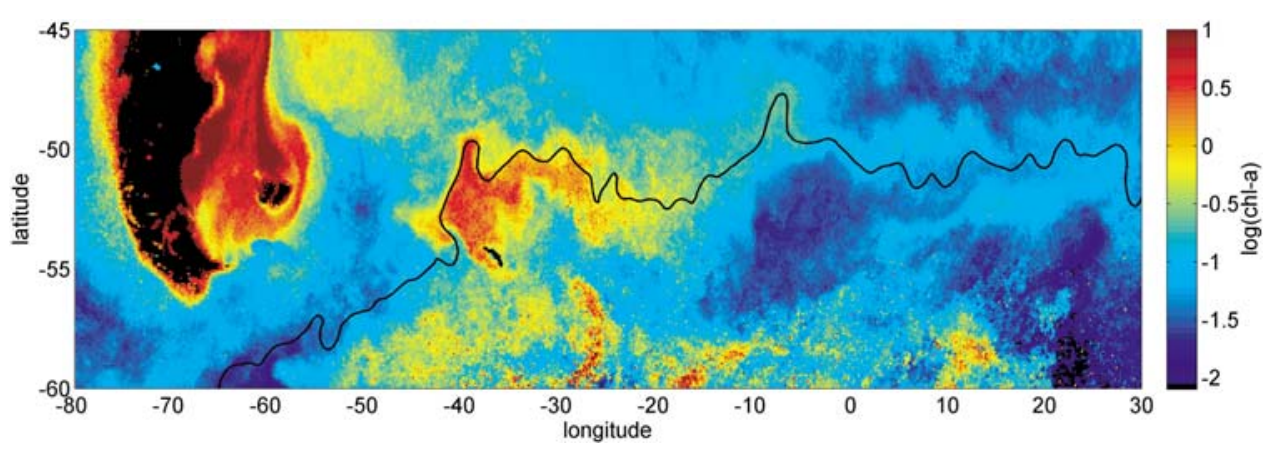

Figure 1. Log(chl-a) image of mean spring (November-December, 1997-2008) SeaWiFS chl-a in the Atlantic sector of the Southern Ocean together with the mean 45 dyn $\mathrm{cm}$ dynamic height contour.

period November to December is chosen as it is after the period of light limitation [Venables and Moore, 2009], which would reduce the links between the distributions of iron and chlorophyll, but before chl-a concentrations drop significantly in the downstream part of the bloom. The black line is a mean dynamic height contour, which is an estimate for a streamline of geostrophic flow in the Polar Front [Sokolov and Rintoul, 2009]. It is apparent that the shape of the bloom north of South Georgia is controlled by the flow around its western and northern edge but the dynamic height contour shown crosses the plume of enhanced chl-a; it lies on its southern side by $\approx 5^{\circ} \mathrm{E}$. This suggests a northward ageostrophic flow of surface waters (and associated iron, phytoplankton and chlorophyll), consistent with a northwards Ekman flux driven by the strong westerly winds.

[7] To investigate this northward flow in detail, the SeaWiFS chl-a data were mapped in dynamic height/ longitude space by averaging into 2.5 dyn $\mathrm{cm} \times 2.5^{\circ}$ longitude bins for each 8-day period between 1 st November and 31st December in the years 1997-2008 (Figure 2). In this coordinate system, geostrophic flow is horizontal to the east but close to South Georgia the actual flow can locally have a westward component so the northern and southern branches of this retroflected flow are combined by this mapping. The extension of high chl-a to dynamic heights greater than 50 dyn $\mathrm{cm}$ between 40 and $30^{\circ} \mathrm{W}$ is likely linked to flow features that have length scales too short to be fully resolved by the absolute dynamic height product [Rio and Hernandez, 2004] but which are resolved better in the higher resolution chl-a data.

\section{Theoretical Ekman and Geostrophic Trajectory}

[8] The region of enhanced chl-a across the South Atlantic is found at gradually higher dynamic heights with distance east (Figure 2). The trajectory through dynamic height/longitude space of a parcel of water in the mixed layer can be predicted from theory using equations of geostrophic flow and Ekman flux [Gill, 1982]. Ekman transport $V\left(\mathrm{~m}^{2} \mathrm{sec}^{-1}\right)$, where $S_{x}$ is the eastward wind stress $\left(\mathrm{N} \mathrm{m}^{-2}\right), \rho$ the density of seawater $\left(\mathrm{kg} \mathrm{m}^{-3}\right)$ and $f$ the Coriolis parameter $\left(\mathrm{sec}^{-1}\right)$ is

$$
V=\left(-S_{x}\right) / \rho f
$$

The long-term average velocity component due to Ekman effects of a water parcel in the mixed layer is therefore $V$ divided by the depth over which this transport is averaged, $d(\mathrm{~m})$. At any given time the spiral of Ekman velocities decays exponentially with depth, with the Ekman depth taken as the depth at which the direction of the current is opposite to that at the surface. At this depth the current strength is $4 \%$ of the surface current [Ekman, 1905]. In our region, the mixed layer is normally deeper than the Ekman depth (Figure 3) [cf. Lenn and Chereskin, 2009; Rio and Hernandez, 2003, Figures 10d and 11d]. If the Ekman depth is shallower than the mld the averaging effect, over long timescales, of parcels of water moving vertically into, through and out of the Ekman layer means that the transport will be averaged over the mld. The error when the mixed layer is shallower than the Ekman depth is reduced by the exponential reduction in Ekman velocities with depth. Accordingly, mixed layer depth has been used in this paper.

[9] Eastward $(u)$ and northward $(v)$ velocities $\left(\mathrm{ms}^{-1}\right)$ are given by equations (2) and (3) respectively, under the assumption that zonal Ekman flux is negligible in the Southern Ocean relative to geostrophic flows due to the predominantly zonal winds and strong zonal currents. $\eta$ is

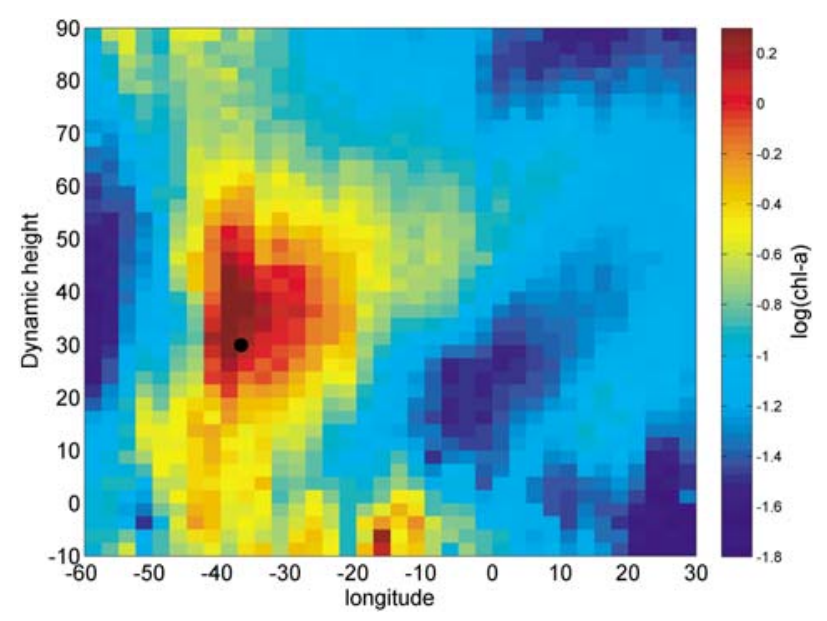

Figure 2. $\log (\mathrm{chl}-\mathrm{a})$ in the Atlantic sector of the Southern Ocean in dynamic height/longitude space. The black spot marks the approximate position of South Georgia. 


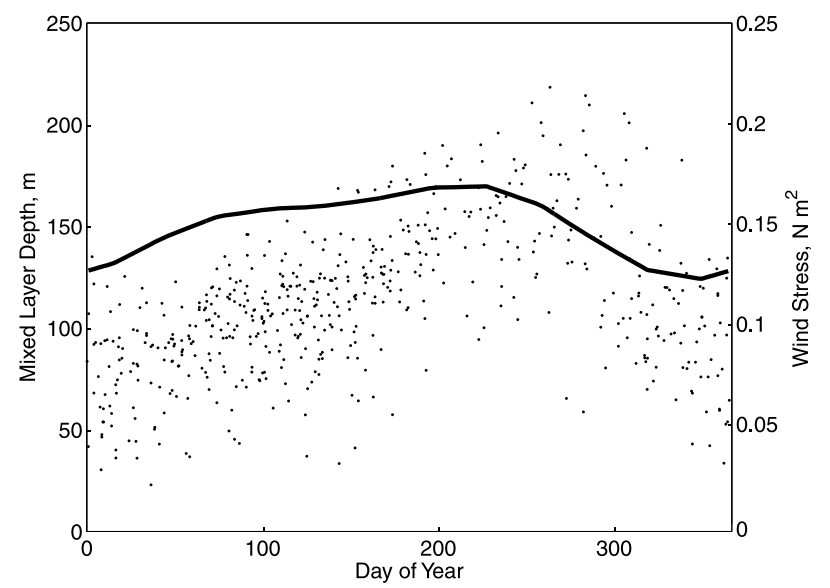

Figure 3. Mixed layer depths (points) from Argo float profiles and monthly mean wind stress from SCOW climatology for the area that gradients were found from: $12.5^{\circ} \mathrm{W}-12.5^{\circ} \mathrm{E}, 30-65$ dyn $\mathrm{cm}$.

dynamic height (dyn m), $g$ gravity, and $d$ the depth over which Ekman flux is averaged, taken to be the mld:

$$
\begin{gathered}
u=\frac{d x}{d t}=\frac{-g}{f} \frac{\partial \eta}{\partial y} \\
v=\frac{d y}{d t}=\frac{g}{f} \frac{\partial \eta}{\partial x}-\frac{S_{x}}{\rho f d}
\end{gathered}
$$

Combining (2) and (3) leads to an expression for the trajectory in latitude/longitude space

$$
\frac{d y}{d x}\left(\frac{g}{f} \frac{\partial \eta}{\partial y}\right)=\frac{-g}{f} \frac{\partial \eta}{\partial x}+\frac{S_{x}}{\rho f d}
$$

Substituting the total derivative for the partial derivative, with the assumption of slow change of dynamic height with time leading to $\partial \eta / \partial t$ being neglected, gives

$$
\frac{g}{f} \frac{d y}{d x}\left(\frac{d \eta}{d y}-\frac{\partial \eta}{\partial x} \frac{d x}{d y}\right)=\frac{-g}{f} \frac{\partial \eta}{\partial x}+\frac{S_{x}}{\rho f d}
$$

This simplifies (the cancelling terms being those that would not have appeared if the calculation had been framed in dynamic height/longitude space) to:

$$
\frac{d \eta}{d x}=\frac{S_{x}}{\rho g d}
$$

This expression is independent of the meridional separation of the dynamic height contours and the Coriolis parameter $f$. The lack of dependence on $f$ indicates an independence from latitude. However, when mapping against longitude there is a dependence on latitude through the zonal distance between lines of longitude.

[10] The important ratio in equation (6) is between wind stress and mld, $\rho \mathrm{g}$ being effectively constant. Wind stress and mld co-vary in time and space so this ratio therefore may be expected to show lower seasonal and spatial variation than either parameter individually (Figure 3).

\subsection{Predictions of Trajectory From Data}

[11] $S_{x} / d$ can be estimated using the monthly wind stress climatology and the monthly-mean mixed layer depths derived from Argo. The seasonal pattern is shown in Figure 3 for the region $49-51^{\circ} \mathrm{S}, 12.5^{\circ} \mathrm{W}-12.5^{\circ} \mathrm{E}$. This area is chosen because the observed gradient is most easily determined in this region (Figure 2).

[12] Eastward geostrophic velocities show a mean flow of $0.09 \mathrm{~ms}^{-1}$ for $49-51^{\circ} \mathrm{S}, 12.5^{\circ} \mathrm{W}-12.5^{\circ} \mathrm{E}$. This leads to a timescale of approximately 220 days for water to pass through the study area. Together with the averaging period for chl-a of November and December, this implies that April to December is the relevant period for determining values of $S_{x} / d$.

[13] The April to December mean ratio of wind stress to mixed layer depth is $S_{x} / d=1.22 \times 10^{-3} \mathrm{~N} \mathrm{~m}^{-3}$, with a range over different months of $(0.99,1.47) \times 10^{-3} \mathrm{~N} \mathrm{~m}^{-3}$. The range from increasing or decreasing each monthly mean mld by two standard deviations is $(1.14,1.32) \times$ $10^{-3} \mathrm{~N} \mathrm{~m}^{-3}$.

[14] This ratio is sensitive to the criteria used to define the mld. Common quantifications of mixed layer depths include part of the density gradient at the base of the mixed layer so the relevant dynamically active slab may be less than the depth estimated. Equally water exchange through mixed layer deepening events may mean that the relevant depth is closer to the maximum observed mld rather than the mean. The sensitivity to the criteria can be shown by using $\Delta \sigma=$ $0.03 \mathrm{~kg} \mathrm{~m}^{-3}$, giving an annual mean of $1.33 \times 10^{-3} \mathrm{~N} \mathrm{~m}^{-3}$ with \pm 2 s.d. range for $d$ of $(1.23,1.46) \times 10^{-3} \mathrm{~N} \mathrm{~m}^{-3}$ and $\Delta \sigma=0.10 \mathrm{~kg} \mathrm{~m}^{-3}$, giving an annual mean of $1.08 \times$ $10^{-3} \mathrm{~N} \mathrm{~m}^{-3}$ and range of $(1.02,1.15) \times 10^{-3} \mathrm{~N} \mathrm{~m}^{-3}$. These estimates translate to estimates for $S_{x} / \rho d g=1.23 \times$ $10^{-7}$ dyn m m${ }^{-1}\left(\Delta \sigma=0.05 \mathrm{~kg} \mathrm{~m}^{-3}\right), 1.34 \times 10^{-7}$ dyn $\mathrm{m} \mathrm{m}^{-1}\left(\Delta \sigma=0.03 \mathrm{~kg} \mathrm{~m}^{-3}\right)$ and $1.09 \times 10^{-7} \mathrm{dyn} \mathrm{m} \mathrm{m}^{-1}$ for $\Delta \sigma=0.10 \mathrm{~kg} \mathrm{~m}^{-3}$.

\subsection{Observations of Trajectory}

[15] Following the maximum chl-a values between $12.5^{\circ} \mathrm{W}$ and $12.5^{\circ} \mathrm{E}$ in Figure 2 gives an observed gradient, with $95 \%$ confidence interval, of $d \eta / d x=0.88 \pm 0.22 \mathrm{dyn} \mathrm{cm}$ (degree longitude) $^{-1}$. Converting the units, for the representative latitude of $50^{\circ} \mathrm{S}$, gives $d \eta / d x=1.2 \pm 0.3 \times 10^{-7}$ dyn m $\mathrm{m}^{-1}$. This is in good agreement with the estimates of $S_{x} / \rho d g$ from observations, given the potential for errors associated with defining and measuring the mld, estimating the gradient in Figure 2 and possible systematic errors such as in the estimation of wind stress over the Southern Ocean. This agreement supports the theory developed here that explains the balance of processes controlling the trajectory of surface water downstream of South Georgia.

\section{Extent of chl-a Downstream of South Georgia}

[16] Figures 1 and 2 show that the enhanced chl-a associated with iron supply from South Georgia decreases to the east, with the signal discernable as far as $15^{\circ} \mathrm{E}$, over $3500 \mathrm{~km}$ downstream. By this longitude, concentrations are as low as $0.3 \mathrm{mg} \mathrm{m}^{-3}$, similar to the background level. The long term averaging removes the effects of transient eddies 
on the chl-a distribution [Kahru et al., 2007] though the theory shows that the trajectory found is independent of the latitudinal separation of geostrophic contours. This means that only the net ageostrophic fluxes induced by mesoscale flows are important. The ageostrophic fluxes of eddies are likely to be spread over greater depths than wind forcing so will induce lower velocities in the mixed layer, even if the fluxes are the same. This is the subject of ongoing work.

[17] The above observations and theory indicate that iron and phytoplankton in the mixed layer move under the dual influences of geostrophic and Ekman flow. Iron below the mixed layer will however move predominantly with the geostrophic flow, therefore horizontally in Figure 2. The enhanced chl-a extends horizontally to $\approx 20^{\circ} \mathrm{W}$ with the chl-a increasing relative to the downstream effects of the Antarctic Peninsula and nearby islands that also reach this position. It is therefore likely that this enhanced chl-a marks the addition into the mixed layer of iron that has been transported subsurface from South Georgia by dominantly geostrophic flows. East of $20^{\circ} \mathrm{W}$ the remaining signal moves across geostrophic contours, from $\approx 50 \mathrm{dyn} \mathrm{cm}$ at $10^{\circ} \mathrm{W}$ to $\approx 65$ dyn $\mathrm{cm}$ at $10^{\circ} \mathrm{E}$, implying that the iron is predominantly confined to the surface layer with subsurface iron concentrations having been depleted. In situ measurements are needed to test this hypothesised iron distribution.

\section{Discussion}

[18] This work demonstrates the basin-scale extent of the influence of the natural iron fertilisation from South Georgia. The monotonic decrease in chl-a shows that the enhanced chl-a values observed in the Atlantic sector of the Polar Front are predominantly due to horizontal advection rather than mesoscale motions inducing upwelling. To first order, this horizontal advection determines the shape of the region of enhanced chl-a. This work also quantifies, from theory and observations, the influence of Ekman flux moving surface water northwards across geostrophic contours. This ageostrophic flow has important implications for the advection of planktonic plants and animals that spend all or part of their lives in the mixed layer and which, over generations, need to remain in the ACC.

[19] The large length scales and long timescale of the bloom also have implications for iron cycling processes that must be occurring to maintain the bloom, especially as iron supply from beneath is limited to the first third of the length of the plume of enhanced chlorophyll. The cycling of iron relative to carbon is one of the key processes that determine the magnitude of the effects of the biological pump in the Southern Ocean. This work helps to set a framework for further investigations in the area over the range of productivity levels found along the length of the bloom.

[20] The agreement between theory and observations helps to validate estimates of Ekman flux in the Southern Ocean, an important component of the global overturning circulation [Sloyan and Rintoul, 2001]. This flux shows significant variability on timescales less than a year [Aoki, 2002]. On longer timescales, there have been increases in wind stress over the Southern Ocean in recent decades [Marshall, 2003] due at least partially to anthropogenic influences (greenhouse gas emissions and/or ozone depletion), with likely consequences for the Ekman flux. Climatic changes in mld due to changes in wind and buoyancy forcing will also affect the chl-a distribution, by changing the depth over which the Ekman flux is averaged. The future relative balance of these factors is not presently clear, but will exert an influence on the distribution of chl-a in this sector of the Southern Ocean. Conversely, recent studies have indicated that ACC flows are relatively invariant compared with the strong changes in atmospheric forcing [Boning et al., 2008; Meredith et al., 2004]. Accordingly, the eastward extent of the bloom is likely to be relatively unaltered if the timescale of iron retention remains unchanged, and whilst the location of the bloom would shift if the geostrophic flow shifted, the trajectory across geostrophic contours has been seen to be independent of the strength of the geostrophic flow.

\section{References}

Aoki, S. (2002), Coherent sea level response to the Antarctic Oscillation, Geophys. Res. Lett., 29(20), 1950, doi:10.1029/2002GL015733.

Blain, S., et al. (2007), Effects of natural iron fertilization on carbon sequestration in the Southern Ocean, Nature, 446, 1070-1074, doi: 10.1038 /nature 05700

Boning, C. W., A. Dispert, M. Visbeck, S. R. Rintoul, and F. U. Schwarzkopf (2008), The response of the Antarctic Circumpolar Current to recent climate change, Nat. Geosci., 1, 864-869, doi:10.1038/ngeo362.

Boyd, P. W., et al. (2007), Mesoscale iron enrichment experiments 1993-2005: Synthesis and future directions, Science, 315, 612-617, doi:10.1126/science. 1131669.

Ekman, V. W. (1905), On the influence of the Earth's rotation on oceancurrents, Ark. Mat. Astron. Fys., 2, 1-52.

Gill, A. E. (1982), Atmosphere-Ocean Dynamics, Academic, San Diego, Calif.

Hewes, C. D., C. S. Reiss, M. Kahru, B. G. Mitchell, and O. Holm-Hansen (2008), Control of phytoplankton biomass by dilution and mixed layer depth in the western Weddell-Scotia Confluence, Mar. Ecol. Prog. Ser, 366, 15-29, doi:10.3354/meps07515.

Kahru, M., B. G. Mitchell, S. T. Gille, C. D. Hewes, and O. Holm-Hansen (2007), Eddies enhance biological production in the Weddell-Scotia Confluence of the Southern Ocean, Geophys. Res. Lett., 34, L14603, doi:10.1029/2007GL030430.

Korb, R. E., and M. J. Whitehouse (2004), Contrasting primary production regimes around South Georgia, Southern Ocean: Large blooms versus high nutrient low chlorophyll waters, Deep Sea Res., Part I, 51, 721-738, doi:10.1016/j.dsr.2004.02.006.

Lenn, Y.-D., and T. K. Chereskin (2009), Observations of Ekman currents in the Southern Ocean, J. Phys. Oceanogr., 39, 768-779, doi:10.1175/ 2008JPO3943.1.

Marshall, G. J. (2003), Trends in the Southern Annular Mode from observations and reanalyses, J. Clim., 16, 4134-4143, doi:10.1175/15200442(2003)016<4134:TITSAM>2.0.CO;2.

Meredith, M. P., P. L. Woodworth, C. W. Hughes, and V. Stepanov (2004), Changes in the ocean transport through Drake Passage during the $1980 \mathrm{~s}$ and 1990s, forced by changes in the Southern Annular Mode, Geophys. Res. Lett., 31, L21305, doi:10.1029/2004GL021169.

Mongin, M., E. Molina, and T. W. Trull (2008), Seasonality and scale of the Kerguelen plateau phytoplankton bloom: A remote sensing and modeling analysis of the influence of natural iron fertilization in the Southern Ocean, Deep Sea Res., Part II, 55, 880-892, doi:10.1016/j.dsr2. 2007.12.039.

Moore, J. K., and M. R. Abbott (2000), Phytoplankton chlorophyll distributions and primary productions in the Southern Ocean, J. Geophys. Res., 105, 28,709-28,722, doi:10.1029/1999JC000043.

O’Reilly, J. E., S. Maritorena, B. G. Mitchell, D. A. Siegel, K. L. Carder, S. A. Garver, M. Kahru, and C. McClain (1998), Ocean color chlorophyll algorithms for SeaWiFS, J. Geophys. Res., 103, 24,937-24,953, doi:10.1029/98JC02160.

Planquette, H., et al. (2007), Dissolved iron in the vicinity of the Crozet Islands, Southern Ocean, Deep Sea Res., Part II, 54, 1999-2019, doi:10.1016/j.dsr2.2007.06.019.

Pollard, R., P. Tréguer, and J. Read (2006), Quantifying nutrient supply to the Southern Ocean, J. Geophys. Res., 111, C05011, doi:10.1029/ 2005JC003076.

Rio, M.-H., and F. Hernandez (2003), High-frequency response of winddriven currents measured by drifting buoys and altimetry over the world ocean, J. Geophys. Res., 108(C8), 3283, doi:10.1029/2002JC001655. 
Rio, M.-H., and F. Hernandez (2004), A mean dynamic topography computed over the world ocean from altimetry, in situ measurements, and a geoid model, J. Geophys. Res., 109, C12032, doi:10.1029/2003JC002226.

Risien, C. M., and D. B. Chelton (2008), A global climatology of surface wind and wind stress fields from eight years of QuikSCAT scatteromete data, J. Phys. Oceanogr., 38, 2379-2413, doi:10.1175/2008JPO3881.1.

Sloyan, B. M., and S. R. Rintoul (2001), Southern limb of the global deep overturning circulation, J. Phys. Oceanogr., 31, 143-173, doi:10.1175 1520-0485(2001)031<0143:TSOLOT>2.0.CO;2.

Sokolov, S., and S. R. Rintoul (2009), The circumpolar structure and distribution of the Antarctic Circumpolar Current fronts: 1. Mean circumpolar paths, J. Geophys. Res., 114, C11018, doi:10.1029/2008JC005108.

Venables, H. J., and C. M. Moore (2009), Phytoplankton and light in the Southern Ocean: Learning from high nutrient high chlorophyll areas, J. Geophys. Res., doi:10.1029/2009JC005361, in press.
Venables, H. J., R. T. Pollard, and E. E. Popova (2007), Physical conditions controlling the early development of a regular phytoplankton bloom north of the Crozet Plateau, Southern Ocean, Deep Sea Res., Part II, 54, 1949-1965, doi:10.1016/j.dsr2.2007.06.014

Whitehouse, M. J., R. E. Korb, A. Atkinson, S. E. Thorpe, and M. Gordon (2008), Formation, transport and decay of an intense phytoplankton bloom within the high-nutrient low-chlorophyll belt of the Southern Ocean, J. Mar. Syst., 70, 150-167, doi:10.1016/j.jmarsys.2007.05.003.

M. P. Meredith and H. J. Venables, British Antarctic Survey, High Cross, Madingley Rd., Cambridge CB3 0ET, UK. (hjv@bas.ac.uk) 